\title{
ADOLESCENTE EM CONFLITO COM A LEI: O RELATÓRIO PSICOSSOCIAL COMO FERRAMENTA PARA PROMOÇÃO DO DESENVOLVIMENTO
}

\author{
Liana Fortunato Costa* \\ Maria Aparecida Penso" \\ Maria Fátima Olivier Sudbrack ${ }^{\infty}$ \\ Olga Maria Pimentel Jacobina ${ }^{\phi}$
}

\begin{abstract}
RESUMO. O objetivo do texto é discutir a construção do relatório psicossocial que é enviado ao juiz, sobre adolescentes em conflito com a lei. Propomo-nos discutir como este relatório pode ser construído de modo a não beneficiar unicamente o juiz e ser um instrumento de enriquecimento do processo jurídico e de ampliação da visão dos atores do judiciário sobre a fase de desenvolvimento do adolescente. $\mathrm{O}$ documento não deve ser elaborado em uma visão apenas avaliativa, mas de modo a devolver a humanidade aos sujeitos dependentes das decisões judiciais e promover uma perspectiva de intervenção psicossocial. Este relatório deve ser útil, correto e justo para com o adolescente. Sua construção precisa valorizar a família e reconhecer sua realidade socioeconômica, basear-se na perspectiva da fase de desenvolvimento deste sujeito, enfocar a circularidade das relações que ele mantém em seu meio ambiente e resgatar a proteção que lhe é devida.
\end{abstract}

Palavras-chave: Adolescente em conflito com a lei; relatório psicossocial; direitos humanos.

\section{ADOLESCENT IN CONFLICT WITH THE LAW: THE PSYCHOSOCIAL REPORT AS A TOOL FOR THE PROMOTION OF DEVELOPMENT}

\begin{abstract}
The aim of the text is to discuss the preparation of the psychosocial report about adolescents in conflict with the law which is sent to the judge. We propose to discuss how this report can be constructed in a way not to benefit only the judge but rather to be an instrument to enrich the juridical process, to enlarge the view of the actors of the judiciary about the phase of the adolescent development, containing not only an evaluation view, returning humanity to subjects dependent on judicial decisions, and promoting a perspective of psychosocial intervention. How can this report be useful, correct and fair to the teenager? Its construction needs: to value the family and to recognize its socio-economic reality, to base on the perspective of the development phase of this subject; to focus on the circularity of the relationships he has in his environment and to rescue the protection due to this adolescent.
\end{abstract}

Key words: Adolescent in conflict with the law; psychosocial report; human rights.

\section{ADOLESCENTE EN CONFLICTO CON LA LEY: EL RELATORIO PSICOSOCIAL COMO HERRAMIENTA DE PROMOCIÓN DEL DESARROLLO}

RESUMEN. El objetivo del texto es el de crear una discusión acerca de la construcción del informe psicosocial que se envía al juez, sobre adolescentes en conflicto con la ley. Proponemos discutir como este informe se puede construir de modo a no beneficiar solamente al juez y, más bien ser un instrumento de enriquecimiento del proceso jurídico, de ampliación de la visión de los actores del judiciario sobre la fase de desarrollo del adolescente, conteniendo, además de una visión evaluativa, el desenvolvimiento de la humanidad a los sujetos dependientes de las decisiones judiciales y promocionando una perspectiva de intervención psicosocial. ¿Cómo este informe puede ser útil, correcto y justo con el adolescente? Su construcción necesita:

Doutorado em Psicologia Clínica pela Universidade de São Paulo, Brasil(1998). Professor Adjunto da Universidade de Brasília , Brasil.

II Doutorado em Psicologia pela Universidade de Brasília, Brasil(2003). Professor titular da Universidade Católica de Brasília , Brasil.

x Doutorado em Doctorat En Psychologie pelo Universite de Paris XIII (Paris-Nord), França(1987). Professor titular da Universidade de Brasília , Brasil

$\Phi$ Doutorado em Psicologia Clínica pela Universidade de Brasília, Brasil(2011). Psicóloga do Secretaria de Desenvolvimento Social e Tranferência de Renda, Brasil 
valorizar la familia y reconocer su realidad socioeconómica; basarse en la perspectiva de la fase de desarrollo de este sujeto; enfocar la circularidad de las relaciones que él mantiene con su entorno y rescatar la protección al adolescente.

Palabras-clave: Adolescente en conflicto con la ley; informe psicosocial; derechos humanos..

O objetivo do texto é discutir a construção do relatório psicossocial que é enviado ao juiz sobre adolescentes em conflito com a lei. Este relatório é elaborado para oferecer ao magistrado um maior conhecimento sobre estes sujeitos, subsidiar suas decisões com informações mais qualificadas e, possivelmente, servir como peça de intervenção. $\mathrm{O}$ documento é solicitado pelo juiz após a decretação de uma medida socioducativa, como prevê o Estatuto da Criança e do Adolescente (ECA) (1990), e tramita na Vara de Infância. Os estudos são realizados por profissionais psicossociais (psicólogos, assistentes sociais, pedagogos integrantes do Judiciário), os quais oferecem suporte para aprofundar o conhecimento sobre o sujeito e sua realidade sociocomunitária e familiar.

Os autores de língua inglesa (por exemplo, Mandeville-Norden \& Beech, 2006; Calhoun, Glaser \& Bartolomucci, 2001; Vess, Ward \& Collie, 2008) enfocam prioritariamente, nos relatórios encaminhados ao juiz, a questão da avaliação de risco (risk assessment). Esses documentos contêm indicadores objetivos, obtidos mediante a aplicação de instrumentos com enfoque estatístico, e podem subsidiar a decisão judicial e torná-la mais acurada, pois apontam índices e tabelas discriminatórias de periculosidade e/ou possibilidade de reincidência em atos infratores. Essa preocupação diz respeito aos atos delinquentes, tanto aos que causam prejuízo social como aos que provocam danos de ordem sexual a crianças ou adolescentes.

$\mathrm{Na}$ realidade brasileira temos dois fatores a considerar: a escassa produção da literatura sobre avaliação psicossocial do adolescente para subsidiar a decisão judicial e nossa legislação, a qual não estabelece diferença entre o adolescente que cometeu ato infracional e o que cometeu ofensa sexual, tratando-os como adolescentes infratores (ECA, 1990). Neste sentido, os textos da literatura internacional podem nos ajudar a discutir a construção dessa avaliação, independentemente da categoria de ato infracional a que nos estejamos referindo.

Propomo-nos discutir como este relatório pode ser construído de modo a não beneficiar unicamente o juiz, ser um instrumento de enriquecimento do processo jurídico e de ampliação da visão dos atores do judiciário sobre a fase de desenvolvimento do adolescente e não conter somente uma visão avaliativa, mas também o sentido de devolver a humanidade aos sujeitos dependentes das decisões judiciais e promover uma perspectiva de intervenção psicossocial. É preciso atentar para as condições de direitos violados, de carências múltiplas, de baixa escolaridade, de vulnerabilidade social em que se encontram os nossos adolescentes.

Os dados, sobre situação da infância e da adolescência no Brasil indicam que os avanços da legislação não transformaram a realidade de crianças e adolescentes despojados de seus direitos básicos. Os adolescentes e jovens (de dez a vinte e quatro anos) representam $29 \%$ da população mundial, e destes, $80 \%$ vivem em países em desenvolvimento. No Brasil, são cerca de 33 milhões de crianças com até nove anos e aproximadamente 35 milhões de 10 a 19 anos portanto a população entre 0 e 19 anos chega a mais de 68 milhões de crianças e jovens, correspondendo a cerca de $30,33 \%$ da população nacional, segundo o último censo do Instituto Brasileiro de Geografia e Estatística (IBGE, 2007). Grande parte desta população vive nos grandes centros urbanos e uma parcela significativa vive em condições desfavoráveis ao seu desenvolvimento.

Por outro lado, as estatísticas têm mostrado que os jovens brasileiros são muito mais vítimas da violência do que agressores. De acordo com as conclusões do "Mapa da Violência IV: os jovens do Brasil", da Unesco (2004) ${ }^{1}$, os avanços da violência homicida das últimas décadas no Brasil são explicados exclusivamente pelo crescimento do número de homicídios contra a juventude. Enquanto os índices de homicídio entre os jovens saltaram de 30 em 1980 para 54,5 de cada cem mil jovens em 2002, os índices referentes ao restante da população permaneceram praticamente estáveis no mesmo período, passando de 21,3 para 21,7 a cada cem mil habitantes). Se na população total houve aumento, entre 1993 e 2002, de $62,3 \%$ nas taxas de homicídios, entre os jovens as taxas aumentaram $88,6 \%$ no mesmo período. Ainda segundo aquele documento da Unesco, em 2002, $39,9 \%$ das mortes de jovens no Brasil deveram-se a homicídios.

Esses dados colocam nossos adolescentes em posição muito diferenciada em relação à juventude dos países do Primeiro Mundo. Este texto se alinha com os

http://www.unesco.org.br 
de outros autores, como Castro e Guareshi (2008); Estevam, Coutinho e Araujo (2009); Gallo (2008), os quais vêm criticando a elaboração deste relatório com base em avaliações prioritariamente psicopatológicas, com definições e prognósticos sombrios acerca dos atos infracionais, esquecendo-se de que a adolescência é uma etapa transitória da vida. O relatório precisa ser pensado com muito cuidado, para que não seja mais um instrumento de controle e classificação de um sujeito que está vivendo uma fase de transição e de experimentação de papeis e formas de inserção no mundo. Isto significa que é preciso entender o adolescente por trás do ato infracional, além de considerá-lo como sujeito a ser protegido.

\section{O ECA E O CONTEXTO DE APLICAÇÃO DAS MEDIDAS SOCIOEDUCATIVAS}

As medidas socioeducativas são dispositivos jurídicos aplicados quando se verifica a prática de ato infracional por adolescente. $\mathrm{O}$ ato infracional é uma conduta descrita pela legislação como crime ou contravenção penal (Castro \& Guareschi, 2008). As medidas aplicadas podem ser advertência, obrigação de reparar o dano, prestação de serviço à comunidade (PSC), liberdade assistida (LA), inserção em regime de semiliberdade e internação em estabelecimento educacional (art. $112^{\circ}$ do ECA).

De acordo com a Política Nacional de Assistência Social (PNAS) (2004) $)^{2}$ as medidas socioeducativas PSC e LA deveriam ser atendidas pelos CREASs (Centros de Referência em Assistência Social) locais. É importante marcar uma mudança paradigmática no tocante ao atendimento prestado aos adolescentes e suas famílias, pois a implementação da PNAS é norteada por uma política nacional, e não mais por uma política de governo. Isto significa que, independentemente da organização governamental do momento, existe uma política que regulamenta os eixos nos quais a execução do atendimento deverá se basear.

Outro marco importante que regulamenta a implementação e execução das medidas socioeducativas é o Sistema Nacional de Atendimento Socieducativo (SINASE) (Brasil, 2006). Sua implementação objetiva primordialmente o desenvolvimento de uma ação socioeducativa assentada nos princípios dos direitos humanos. Esse sistema propõe diretrizes para uma política pública voltada à implementação das medidas socioeducativas

\footnotetext{
2 http://www.sedest.df.gov.br/sites/300/382/00000877.pdf
}

previstas no ECA e estabelece um conjunto de regras e critérios de caráter jurídico, político, pedagógico, financeiro e administrativo que devem ser seguidos durante o processo de apuração de ato infracional cometido por adolescentes até a execução de medidas socioeducativas. Além disso, propõe as medidas em meio aberto (prestação de serviço à comunidade PSC - e liberdade assistida - LA) em preferência às restritivas de liberdade, as quais somente devem ser aplicadas em caráter excepcional, nos casos de atos infracionais mais graves. O documento orienta, ainda, para a articulação das políticas intersetoriais em nível local e a constituição de redes de apoio nas comunidades.

Convém reiterar que tanto a Declaração Universal dos Direitos da Criança, emitida pelas Nações Unidas em 1959 na Convenção da Organização das Nações Unidas (ONU), quanto o ECA, preveem a aplicação de medidas socioeducativas quando atos infracionais são cometidos por adolescentes, mas asseguram, ao mesmo tempo, que essa medida aplicada judicialmente será a única punição que incidirá sobre pessoas daquela faixa etária (Neto, 1999). Preveem, além disso, a possibilidade de aplicação concomitante de medidas protetivas, na intenção de restabelecer direitos violados, portanto supõe que a prática do ato infracional pode estar correlacionada, em algum nível, com a violação dos direitos fundamentais.

A Doutrina da Proteção Integral está presente na Constituição Federal (1988) e no ECA, e representa uma ruptura com o pensamento do direito anterior, que se constituía no direito do menor. O direito do menor traduzia uma perspectiva de infância delinquente, característica de uma tradição autoritária do Direito, enquanto a perspectiva dos direitos humanos, que é a base filosófica da proteção integral, identifica uma infância carente. Os dois paradigmas são contraditórios: um está preocupado em acusar e punir, o outro busca proteger e oferecer condições de mudança na realidade de vida do adolescente (Machado, 2003). A Doutrina de Proteção Integral foi consagrada a partir de uma convenção da ONU e vem inspirando toda a legislação sobre a infância e a adolescência, na perspectiva de que estas duas etapas de vida da pessoa humana requerem uma atenção especial, por se tratar de seres em formação.

\section{O PLANO INDIVIDUAL DE ATENDIMENTO - PIA}

O SINASE, que se constitui em uma política pública em interface com os sistemas estaduais, distrital e municipais e com as políticas de educação, saúde, trabalho, previdência social, assistência social, 
cultura, esporte, lazer, segurança pública e outras, e com programas destinados a concretizar a proteção integral dos adolescentes em conflito com a lei, criou a obrigatoriedade do PIA (Plano Individual de Atendimento) (Brasil, 2006). Esse plano é um instrumento de planejamento, registro e gestão das atividades a serem desenvolvidas com o adolescente como medidas socioeducativas postulado pelos envolvidos na execução da medida. O propósito fundamental do PIA é a personalização do atendimento ao jovem em conflito com a lei; portanto o PIA se configura como uma ferramenta importante para a evolução pessoal e social do adolescente e para a conquista de metas e compromissos estabelecidos no decorrer da medida e adequação às necessidades do adolescente e sua família e como ponto central da estruturação da execução da medida socioeducativa.

Isto significa que o PIA será utilizado na construção de metas e compromissos pactuados com os jovens que cumprem medidas socioeducativas e suas famílias os quais consistem no acompanhamento, avaliação e evolução pessoal e social desses jovens, propiciando maior concretude em relação aos seus avanços e/ou retrocessos no processo socioeducativo. Este Plano prevê momentos de intervenção diferenciados pelas várias áreas que atendem os adolescentes em medida socioeducativa, iniciando-se no processo de acolhimento e devendo ser concluído após 15 dias no caso de internação provisória e 45 dias no de internação estrita. É importante ressaltar que tais intervenções precisam ser caracterizadas por abordagens adequadas às necessidades específicas de cada adolescente e sua família e voltadas à sua evolução pessoal e social, considerando as dimensões social e coletiva. Devem ser abordadas de forma multiprofissional e interdisciplinar, envolvendo os diferentes aspectos que interagem no cotidiano dos adolescentes no contexto em que estão inseridos, suas potencialidades e sua capacidade de enfrentamento e superação de dificuldades.

No caso do cumprimento da medida de internação, o PIA só poderá ser construído a partir de uma proposta de diagnóstico polidimensional e individualizado, com definição de ações a serem implementadas, compreendendo a situação processual e as providências necessárias, a fixação das metas a serem alcançadas pelo adolescente e a definição das atividades internas e externas, individuais ou coletivas das quais o adolescente irá participar, inclusive as condições para o exercício da sexualidade e as medidas especiais de atenção à saúde. Além disso, a elaboração, acompanhamento e reavaliação do PIA incluem discussões permanentes em encontros periódicos, quinzenais e/ou quando necessários com a equipe multiprofissional de referência do adolescente e sua família. Assim, o PIA deverá estar sempre sujeito a reformulações de acordo com o processo evolutivo do adolescente ou quando forem necessárias, por demanda do adolescente, dos familiares ou dos profissionais responsáveis pelo atendimento do jovem.

\section{O RELATÓRIO PSICOSSOCIAL ELABORADO SOBRE O ADOLESCENTE EM CONFLITO COM A LEI}

Em primeiro lugar, é importante lembrar que em nossa realidade o cometimento de atos infracionais, na grande maioria dos casos, está associada a contextos de pobreza e vulnerabilidade social. Segundo o IBGE, em 2004 o Brasil tinha 25 milhões de adolescentes na faixa de 12 e 18 anos, o que representa cerca de $15 \%$ da população de um país marcado por uma intensa desigualdade social e concentração de renda, pois $01 \%$ da população detém $13,5 \%$ da renda nacional, enquanto os $50 \%$ mais pobres detêm 14,4\% (IBGE, 2004). Isto significa que temos um grande número de adolescentes excluídos, sem perspectivas de inclusão no mercado formal de trabalho, vivendo em um contexto de grande oferta de drogas, armas e inserção no tráfico de drogas. São adolescentes que vivem em situação de vulnerabilidade social e necessitam sobreviver, o que muitas vezes só é possível por meio de uma integração perversa, na expressão de Guareshi (2004). Este autor, referindo-se à obra de Manuel Castells (citado por Guareshi, 2004), ao avaliar a dinâmica social do capitalismo informacional aponta que esta integração perversa se dá pelo trabalho em uma economia criminosa, isto é, em atividades de geração de renda que a lei declara criminosas, como o tráfico de drogas, o contrabando, extorsões e outras.

A delinquência só é reconhecida depois que a sentença precisa é conhecida, avaliada, medida, diagnosticada e tratada, mas mesmo assim é preciso muito cuidado para não transformar o infrator em delinquente (Foucault, 1986). Para isto é necessário fazer uma cuidadosa avaliação das condições individuais, familiares e sociais do adolescente que cometeu um ato infracional, sem construir para ele um perfil de delinquente. Recorremos a Foucault (1986) para diferenciar essas duas nomeações. Para esse filósofo, o infrator é definido como aquele que infringiu as normas jurídicas estabelecidas, enquanto o delinquente é fabricado e submetido ao sistema judiciário, que o nomeia, estigmatiza e controla.

Ainda segundo Foucault (1986, p. 211), 
$\mathrm{O}$ delinquente se distingue do infrator pelo fato de não somente ser o autor do seu ato (autor responsável em função de certos critérios da vontade livre e consciente), mas também de estar amarrado a seu delito por um feixe de fios complexos (instintos, pulsões, tendências, temperamento).

Autores como Vess et al. (2008), MandevilleNorden e Beech (2006), Scheela (2001), defendem que o relatório sobre os riscos de reincidência em atos infratores seja também avaliado do ponto de vista qualitativo, mostrando que o estudo de caso pode beneficiar sobremaneira a compreensão da dinâmica dessas atuações. Essa dimensão mais compreensiva pode alterar positivamente os encaminhamentos feitos para o adolescente (Vess et al., 2008). Na verdade, esses autores concordam com uma complementaridade entre a aplicação de medidas objetivas e de medidas compreensivas.

A partir de nossa experiência, reconhecemos que em nosso país não temos o hábito de avaliar por meio de instrumentos validados. Poderíamos mesmo dizer que há quase um preconceito em relação à medição dos riscos de reincidência em atos delinquentes. Talvez isto se deva ao reconhecimento de que essa população autora de atos violentos é, ela mesma, extremamente violentada. Uma exceção a esse modus operandi encontramos em Padovani e Williams (2005), que fizeram um estudo de caso envolvendo medidas objetivas.

Para o acompanhamento da medida socieducativa e/ou para a elaboração de uma sentença final no processo o juiz precisa conhecer aspectos subjetivos do adolescente. Lima (2003) define o relatório psicossocial como um estudo, realizado por psicólogos e assistentes sociais de um tribunal de justiça que "assessoram nas decisões dos magistrados em questões referentes às famílias procurando promover pequenas intervenções no sistema atendido." (p. 16). Não é suficiente conhecer sobre o ato infracional, é preciso também adentrar as motivações que vêm da história de vida do adolescente, sua realidade sociocultural e comunitária e os conflitos familiares que o envolvem (Gallo, 2008). Esta avaliação descentra o processo do ato infracional e o centra no sujeito e sua história, dando visibilidade ao adolescente em sua fase de transição e às complexidades que the são inerentes. Esta avaliação deve ser feita antes da aplicação da medida, já que a avaliação deve subsidiar as orientações e intervenções que acompanham a medida (Gallo, 2008).

Machado (2003) insiste em que a criança e o adolescente sejam vistos como "pessoas em condição especial" (p. 120-121), isto é, pessoas que ainda estão em fase de desenvolvimento e por isso necessitam de proteção e têm direito à possibilidade de formar sua personalidade humana adulta. Esta perspectiva dever ser um aspecto que inspire e oriente quanto aos métodos e instrumentos a serem aplicados na coleta de informações para a elaboração do relatório.

Como foi dito anteriormente, o ECA preconiza a excepcionalidade da decretação de medida restritiva de liberdade, e Estevam, Coutinho e Araújo (2009) chamam a atenção para as responsabilidades institucionais e governamentais no momento em que o juiz decreta esta medida. Se o adolescente é mantido em privação de liberdade, tanto maior se torna a responsabilidade da instituição que o recebe em oferecer-lhe as devidas condições de saúde, educação e profissionalização.

$\mathrm{O}$ que temos observado em nosso contexto de atuação é que estes adolescentes somente recebem esta avaliação quando se encontram nesta condição de excepcionalidade, ou seja, quando estão privados de liberdade. Somente nesse momento é que as instituições responsáveis pelo acompanhamento da medida socieducativa vão buscar conhecer com mais profundidade esse sujeito para assim construir uma avaliação que possa auxiliar o juiz em suas decisões. $\mathrm{O}$ que queremos discutir e problematizar é que o conhecimento sobre esse sujeito dever ser construído de forma que ele seja, além de sujeito de direito, também sujeito de voz e intervenção. Dois textos sobre a efetivação da aplicação de medida socioeducativa esclarecem a respeito da fragilidade desse acompanhamento. Souza e Costa (2011) mostram que no Distrito Federal os recursos alocados para esse fim são escassos e inadequados, revelando descaso e não cumprimento da proteção devida a esses sujeitos. Intuímos que a realidade do Distrito Federal não se encontra muito distante da realidade dos estados da federação. Jacobina e Costa (2011) apontam que há uma sistemática desarticulação do sistema de garantias de direitos que atende o adolescente a quem foi aplicada a medida socioeducativa de liberdade assistida (LA), o que se traduz em violação dos direitos desse adolescente e lhe dificulta a superação das condições que o levaram à prática do ato infracional. Nesse contexto, é preciso que o relatório seja realista, mas favoreça também a proteção do adolescente.

Compartilhamos da posição de Machado (2003) de que a aplicação dos direitos fundamentais surge com o reconhecimento dos direitos sociais que vão garantir ao adolescente infrator proteção e acesso às instituições incumbidas de fornecer-lhe educação, 
profissionalização, inserção social e saúde, condições importantes para desenvolvimento de sua personalidade. Propiciar ou não esta trajetória de recuperação depende do modo como é elaborado esse relatório. A aplicação das medidas socioeducativas como forma de concretização da proteção integral pode encontrar um veículo correto e justo nas argumentações contidas no relatório.

\section{PARA QUEM SERVE O RELATÓRIO}

O relatório, com certeza, subsidia o juiz em sua tarefa, ao trazer aspectos subjetivos do adolescente, mas sua função não é somente esta. O relatório permite conhecer melhor o sujeito em sua realidade social e familiar, e não somente no seu lado delinquente, que é o que mais interessa à Justiça. Embora o interesse da Justiça seja compreender aspectos específicos do ato delinquente, cabe à equipe psicossocial responsável pela elaboração do relatório transformar esta solicitação em uma possibilidade de conhecimento do sujeito e de sua história. Torna-se necessário discutir o olhar da sociedade sobre este sujeito, já que, em função do ato cometido, os estereótipos podem prevalecer sobre a subjetividade. Para Xaud (2000), isto significa abandonar definitivamente o caráter moralista, preconceituoso, preconcebido e discriminatório das velhas práticas, procurando compreender que os aspectos que influenciaram o cometimento do ato infracional são apenas parte de um todo multifacetado. Em função do teor do relatório, são vários os sujeitos que poderão ser construídos: o delinquente, a vítima, o agressor, o bandido e outros, a depender dos estereótipos que podem afetar a subjetividade dinâmica e em constante mudança do adolescente. A medida socioeducativa precisa ser, de fato, socioeducativa no tocante à realidade social do adolescente e promover um avanço no patamar educativo deste sujeito.

A partir da análise dos discursos dos adolescentes em medida de internação e dos relatórios sobre estes adolescentes, Castro e Guareschi (2008) denunciam que tais documentos buscam caracterizar esses adolescentes como marginais e perigosos. A construção linguística é determinista e o conteúdo não resgata a complexidade da vida e da realidade socioeconômica deste sujeito; e o mais grave é que o documento considera os atos infracionais como tendências definitivas e naturais, e não como construções transitórias e possíveis de serem transformadas se lhes forem oferecidas condições reeducativas e ressocializadoras. Brito (2005) sugere aos profissionais que abandonem o cunho pericial e procurem sair do âmbito da investigação de verdades/mentiras deixem de apontar o certo/errado, para ampliar conhecimento e propor intervenção, já que, ao que parece, juízes e advogados esperam que um relatório desvende estes aspectos para assim eles poderem tomar medidas com mais segurança.

Segundo Mandeville-Norden e Beech (2006), o histórico do adolescente infrator que servirá de base para a elaboração do relatório deve conter dados como a história dos atos infracionais, a história dos fatores ambientais que influenciaram esses atos e a história da motivação para sua prática, ou seja, os aspectos afetivo-emocionais do adolescente. Esses autores se posicionam favoravelmente à entrevista clínica como instrumento útil nessa avaliação, a qual, em sua opinião, deve ser complementada por instrumentos do tipo check list. Também alertam que será maior a probabilidade de se errar na predição de comportamentos reincidentes se a opinião emitida no relatório for de caráter eminentemente subjetivo.

A nosso ver, o relatório que muitas vezes é adotado como orientação pelo juiz necessita ser coerente com o conhecimento ecológico sobre o adolescente, sua família e sua realidade sociocomunitária, privilegiando uma equação a partir de sua vulnerabilidade e dos recursos que lhe estão sendo oferecidos para uma mudança na sua trajetória de vida. É necessário que este documento resgate a condição especial de desenvolvimento (Machado, 2003) em que esse sujeito se encontra e que o Estado ofereça acesso aos direitos que lhe foram negados por sua condição de carência. O relatório e a Justiça precisam se colocar como atores no resgate dos direitos sociais de que o adolescente carece, agindo em seu benefício, e não como peças de acréscimo de sua vulnerabilidade.

\section{UTILIDADE DO RELATÓRIO}

O relatório serve para compor uma avaliação, mas também para orientar, transformar, oferecer oportunidade de intervenção e, principalmente, situar o adolescente como pertencente a um tempo histórico, a um tempo pessoal e a um tempo judicial. Reconhecemos que a Justiça ainda não oferece de pronto (posição corroborada por Cesca 2004) uma dimensão reparatória para as situações de violência que levam o adolescente a cometer atos infracionais. A Justiça precisa avançar nesta área, colocando-se em rede com outras instituições que venham a garantir-lhe acesso à saúde, à educação e à assistência social.

Há um aspecto ainda mais grave, que é a violência sofrida pelos adolescentes. Segundo a $1^{\text {a }}$ VIJ-DF / 
SEMSE (2011), os atos de violência mais frequentemente praticados por policiais nos adolescentes são: tapas (17,88\%); socos $(14,61 \%)$; chutes $(14,11 \%)$ e xingamentos $(12,34 \%)$. As áreas do corpo mais atingidas são a cabeça/rosto $(38 \%)$, várias partes do corpo (30\%) e costelas e rins (16\%). A categoria mais violenta é a dos policiais militares (58\%), seguida da dos policiais civis (38\%). Em 77,5 $\%$ dos casos os adolescentes não identificam ou não querem identificar oficialmente os policias agressores.

Este aspecto dificilmente é mencionado nos relatórios, porque estes ainda são pautados em um viés jurídico que dá maior ênfase à criminalidade da pessoa do adolescente infrator, e não à sua potencial vitimização (Cesca, 2004; Machado, 2003). O caráter avaliativo do relatório deve ser contrabalançado por uma perspectiva de planejamento de intervenções que sejam eficazes e ajudem o adolescente a superar a situação de cometimento ao ato infracional. Isto significa que, mais do que avaliar, o relatório precisa fornecer subsídios para orientar o trabalho psicossocial com o adolescente.

Kolker (2004) aponta que há uma enorme diferença na elaboração de relatório sobre um sujeito que está em regime de privação de liberdade e sobre um que não esteja nessa condição. $O$ primeiro poderá ter sua pena acrescida ou alterada desfavoravelmente, dependendo da qualidade da interpretação das informações contidas. Ao adolescente é imposto que colabore com um profissional que poderá, ao final, concorrer para sua insatisfação em relação ao que o estudo ressaltar. Por outro lado, este profissional sabe que o futuro deste adolescente depende da forma como o relatório for escrito e das informações nele colocadas com mais ênfase. Em uma capacitação oferecida à Secretaria de Justiça do Distrito Federal, pudemos observar que os psicólogos, assistentes socais e pedagogos apontaram seu sofrimento na hora de elaborar estes relatórios e seus impasses por terem de apontar condutas dos adolescentes que certamente iriam retardar sua saída das unidades de internação.

O relatório psicossocial, por sua necessária condição de ser uma peça uniforme e coerente, corre o risco de omitir ou minimizar os impasses e contradições presentes no processo de conhecimento e avaliação do adolescente; mas já é possível apontar (Miranda Jr., 2005) as demandas clínicas e/ou de intervenção psicossocial como decorrentes da elaboração do relatório, cuja perspectiva é mais de orientação e transformação do que de estudo e avaliação dos sujeitos.

\section{UM RELATÓRIO ÚTIL, CORRETO E JUSTO PARA COM O ADOLESCENTE}

\section{Servindo a dois senhores}

O relatório precisa ser construído com uma formatação que sirva de peça de subsídio e informações ao juiz, mas deve também enriquecer o modus operandi do judiciário, trazendo a este contexto a realidade social desse sujeito, ampliando a compreensão sobre ele a partir do paradigma de sua inserção no meio social e contemplando as questões éticas implícitas no processo.

\section{Valorizando a família}

As informações sobre as relações familiares dos adolescentes são essenciais. O relatório poderá ser mais correto na medida em que ofereça informações que visualizem a família em seus conflitos e em sua história transgeracional, elementos que resgatarão a violência presente nas gerações anteriores e mostrarão que o adolescente está envolvido numa teia de repetições em que é muito difícil adquirir, sozinho, consciência de que sua conduta reproduz outras das quais é quase impossível ele se livrar (BucherMaluschke, 2007). Esta condição faz parte dos legados inconscientes que são transmitidos de geração a geração e acabam por se constituírem em mitos, em construções intocáveis que norteiam e influenciam as histórias familiares (Penso \& Costa, 2008).

\section{Reconhecendo a realidade socieconômica}

Giffin (2002) aponta que a condição socioeconômica da família molda as oportunidades de seus componentes, especialmente porque a grande maioria dessas famílias é chefiada pela mãe. A pobreza material, a baixa escolaridade, atividades de envolvimento com o uso ou tráfico de drogas e a constante troca de parceiros por parte das mulheres constroem um ambiente de vulnerabilidade que afeta diretamente o adolescente. Este conjunto de aspectos é bem explorado por Penso e Sudbrack (2004) quando falam em uma identidade adolescente inserida numa interdependência emocional entre mãe e filho adolescente. Estes aspectos se encontram nessa específica configuração parental em que o filho assume o papel de provedor e companheiro da mãe em sua tarefa de cuidar da família e mantê-la.

\section{Apoiando a fase de transição}

Machado (2003) fala em "direito de desenvolver a personalidade" (pp. 120-121). Essa autora, ao 
discorrer sobre os direitos humanos de crianças e adolescentes, enfatiza como seu direito fundamental o de serem tratados como pessoas humanas em fase de desenvolvimento, e como tal, seu direito de receber proteção para poderem desenvolver-se e alcançar a maturidade, reivindicando para eles uma condição peculiar de direito de receber assistência devida que proporcione o alcance desta meta. Para isto é necessária a implementação de políticas públicas como instrumento da efetivação desses direitos.

\section{Enfocando a circularidade das relações}

Bucher-Maluschke (2007) aponta um avanço nos estudos avaliativos no âmbito do judiciário no que diz respeito à dimensão qualitativa presente nesses estudos, saindo do limite do psicodiagnóstico e ampliando-se para a consideração de aspectos da ordem do social e das interações que o sujeito mantém em seu meio, os quais podem ser fundamentais para se compreender o ato infracional. $\mathrm{O}$ juiz precisa saber sobre o sujeito, questões que vão muito além do aspecto jurídico. Ademais, o relatório deve conter a inter-relação das partes que compõem os conflitos a que o adolescente está vinculado. Estamos falando de uma discussão que seja circular e evidencie os sentidos contraditórios contidos nos fatos e nas pessoas que envolvem o adolescente.

\section{Resgatando a proteção devida ao adolescente}

Além da compreensão dos elementos que se reúnem no cometimento do ato infracional, é preciso que o relatório contemple corretas relações entre o profissional e o adolescente, já que este documento poderá ser uma peça definitiva na vida do sujeito, marcando-o com um estereótipo que poderá prejudicálo enormemente até o fim de sua vida.

\section{Construindo o PIA}

O relatório deverá indicar os caminhos a serem percorridos na construção do PIA pelas entidades de atendimento e/ou programas que executam a internação provisória e as medidas socioeducativas de prestação de serviço à comunidade, liberdade assistida, semiliberdade e internação.

Esse documento deve inovar no sentido de conhecer mais objetivamente as questões relativas à reincidência em atos infracionais e basear-se em uma visão mais compreensiva a respeito dessas questões. Para Scheela (2001), esse documento necessita conter uma avaliação mais substancial e menos opinativa sobre a condição de reincidência do adolescente em atos infratores. Os profissionais, por sua vez, precisam adotar uma postura menos preconceituosa quando fazem avaliações por meio de instrumentos objetivos (Calhoun et al., 2001) e manter uma intenção protetiva em relação ao adolescente.

\section{À GUISA DE CONCLUSÃo}

Para finalizar, queremos apontar que o relatório sobre o adolescente que está cumprindo medida socieducativa precisa estabelecer o sentido para a aplicação da medida. Esse documento deve resgatar o sentido de que está sendo construída uma nova oportunidade para este sujeito ter seus direitos restabelecidos e de que sua passagem pelo judiciário pode ser o momento desse resgate. Nesse ponto, a Justiça se constitui no contexto que vai criar as condições para que o adolescente recupere sua perspectiva de um ser em formação. O sentido do cumprimento da medida precisa ainda ser resgatado pela família e pelo próprio adolescente, que deverão ter vez e voz, pois isto possibilitará a reconfiguração de suas relações, mediante um diálogo construtivo e capaz de apontar-lhe o sentido da medida disciplinar. Também precisa ser resgatado pelo judiciário, particularmente pela figura do juiz, que deve ver em sua autoridade um momento oportuno para a recriação, para o adolescente infrator, de relações sociais baseadas no respeito e na percepção de seu lugar no meio social.

\section{REFERÊNCIAS}

Brasil. Presidência da República. Secretaria Especial dos Direitos Humanos. Conselho Nacional dos Direitos da Criança e do Adolescente. (2006). Sistema Nacional de Atendimento Socioeducativo. Brasília: CONANDA. Recuperado em 15 fevereiro, de 2010, http://www.condeca.sp.gov.br/legislacao/sinase_integra.pdf.

Brito, L. M. T. (2005). Reflexões em torno da Psicologia Jurídica. In R. M. Cruz, S. K. Maciel \& D. C. Ramirez (Orgs.), O trabalho do psicólogo no campo jurídico (pp. 7-17). São Paulo: Casa do Psicólogo.

Bucher-Maluschke, J. S. N. F. (2007). Revisitando questões sobre lei, transgressão e família em suas interações com a Psicologia, a Psicanálise, o Direito e a interdisciplinaridade possível. Psicologia. Teoria e Pesquisa, 23(n ${ }^{\circ}$ especial), 89-96.

Calhoun, G. B., Glaser, B. A., \& Bartolomucci, C. L. (2001). The juvenile counseling and assessment model and program: A conceptualization and intervention for juvenile delinquency. Journal of Counseling \& Development, 79, 131-141.

Castro, A. L. S., \& Guareschi, P. (2008). Da provação da dignidade social à provação da liberdade individual. Psicologia \& Sociedade, 20(2), 200-207. 
Cesca, T. B. (2004). O papel do psicólogo jurídico na violência intrafamiliar: possíveis articulações. Psicologia \& Sociedade, 16(3), 41-46.

Constituição da República Federativa do Brasil (1988, 5 de outubro). Brasília: Senado Federal.

Estevam, I. D.; Coutinho, M. P. L., \& Araujo, L. F. (2009). Os desafios da prática sócio educativa de privação de liberdade em adolescentes em conflito com a lei: Ressocialização ou exclusão social? Psico, 40(1), 67-72.

Foucault, M. (1986). Vigiar e punir (L. M. P. Vassalo, Trad.) (4a ed.). Rio de Janeiro: Voze. (Original publicado em 1975).

Gallo, A. E. (2008). Atuação do psicólogo com adolescentes em conflito com a lei: a experiência do Canadá. Psicologia em Estudo, 13(2), 327-334.

Giffin, K. (2002). Pobreza, desigualdade e equidade em saúde: considerações a partir de uma perspectiva de gênero transversal. Cadernos de Saúde Pública, 18(suplemento), 103-112.

Guareshi, P. A. (2004). Pressupostos psicossociais da exclusão: competitividade e culpabilização. In B. B. Sawaia (Org.), As Artimanhas da Exclusão : Análise psicossocial e ética da desigualdade social. (pp. 141-156). Petrópolis: Vozes.

IBGE (2004). Pesquisa Nacional por Amostra de Domicílios Recuperado em 15 fevereiro, 2010, de http://www.ibge.gov.br/home/estatistica/populacao/trabalhoerendi mento/pnad2004.

IBGE (2007). Vamos conhecer o Brasil? Recuperado em 2 fevereiro, 2011, de http://www.ibge.gov.br/7a12/conhecer_brasil.

Jacobina, O. M. P. \& Costa, L. F. (2011). Da medida protetiva à socioeducativa: o registro da (des)proteção. Psicologia Política, 11 (21), 123-139.

Kolker, T. (2004). A atuação dos psicólogos no sistema penal. In H. S. Gonçalves \& E. P. Brandão (Orgs.), Psicologia Jurídica no Brasil (pp. 157-204). Rio de Janeiro: Nau.

Lei $n^{\circ}$ 8069, de 13 de julho de 1990. (1990, 13 de julho). Estatuto da Criança e do Adolescente. Recuperado em 15 fevereiro, 2010, de http://portal.mec.gov.br/seesp/arquivos/pdf/lei8069_02.pdf.

Lima, H. G. D. (2003). Apresentação. In H. G. D. Lima (Coord.), Construindo caminhos para a intervenção psicossocial no contexto da Justiça (pp. 15-18). Brasília: TJDFT.

Machado, M. T. (2003). A Proteção Constitucional de Crianças e Adolescentes e os Direitos Humanos. Barueri: Manole.

Mandeville-Norden, R., \& Beech, A. R. (2006). Risk Assessment of Sex Offenders: The Current Position in the UK. Child Abuse Review, 15, 257-272.
Miranda Jr, H. C. (2005). Psicanálise e avaliação psicológica no âmbito jurídico. In S. Shine (Org.), Avaliação psicológica e lei: adoção, vitimização, separação conjugal, dano psíquico e outros temas (pp. 159-174). São Paulo: Casa do Psicólogo.

Neto, W. N. (1999). A Convenção Internacional sobre o Direito da Criança e a Busca do Equilíbrio entre Proteção e Responsabilização. In Sistema de Garantia de Direitos: Um caminho para a Proteção Integral (pp. 29-38). Recife: Centro Dom Helder Câmara de Estudos e Ação Social - CENDHEC.

Padovani, R. C., \& Williams, L. C. de A. (2005). Proposta de intervenção com adolescentes em conflito com a lei: um estudo de caso. Interação em Psicologia, 9 (1), 117-123.

Penso, M. A., \& Costa, L. F. (Orgs.) (2008). A transmissão geracional em diferentes contextos. Da pesquisa à intervenção. São Paulo: Summus.

Penso, M. A., \& Sudbrack, M. F. O. (2004). Envolvimento em atos infracionais e com drogas como possibilidade para lidar com o papel do filho parental. Psicologia USP, 15(3) 29-54.

Scheela, R. A. (2001). Sex offender treatment: therapist's experiences and perceptions. Issues in Mental Health Nursing, 22, 749-767.

Souza, L. A., \& Costa, L. F. (2011). Liberdade Assistida no Distrito Federal: impasses na implementação das normativas do SINASE e do SUAS. Revista Brasileira de Adolescência e Conflitualidade, 4, 117-134.

Tribunal de Justiça do Distrito Federal e dos Territórios (2011). A violência policial na voz dos adolescentes em conflito com a lei. Brasília: O Tribunal. Recuperado em 15 fevereiro, 2010, de http://www.tjdft.jus.br/trib/vij/docVij/violencia_policial.pdf.

Vess, J., Ward, T., \& Collie, R. (2008). Case formulation with offenders: An illustration of individualized risk assessment. Journal of Behavior Analysis of Offender and Victim Treatment and Prevention, 1 (3), 284-293.

Xaud, G. M. B. (2000). Os desafios da intervenção psicológica na promoção de um nova cultura de atendimento do adolescente em conflito com a lei. In L. M. T. de Brito (Org.), Temas de Psicologia Jurídica (2a ed.) (pp. 87-102). Rio de Janeiro: Relume Dumará.

Recebido em 22/03/2010 Aceito em 07/11/2011
Endereço para correspondência:
Liana Fortunato Costa. SQN 104 Bloco D ap. 307, CEP 70733-040, Brasília-DF, Brasil. E-mail:lianaf@terra.com.br. 